\title{
Reliability and Validity of the Audit on Diabetes-Dependent Quality of Life (ADDQoL) and EQ-5D in Elderly Slovenian Diabetes Mellitus Type 2 Patients
}

\author{
Eva Turk ${ }^{*}$, Valentina Prevolnik Rupel ${ }^{2}$, Alojz Tapajner ${ }^{3}$, Arja Isola ${ }^{4}$ \\ ${ }^{1}$ DNV GL Strategic Research and Innovation, Healthcare Programme, Høvik, Norway \\ ${ }^{2}$ Institute for Economic Research, Ljubljana, Slovenia \\ ${ }^{3}$ Faculty of Medicine, University of Maribor, Maribor, Slovenia \\ ${ }^{4}$ Faculty of Medicine, Institute of Health Sciences, University of Oulu, Oulu, Finland \\ Email: ${ }^{*}$ Eva.turk@dnvgl.com
}

Received 8 January 2014; revised 12 February 2014; accepted 20 February 2014

Copyright (C) 2014 by authors and Scientific Research Publishing Inc.

This work is licensed under the Creative Commons Attribution International License (CC BY).

http://creativecommons.org/licenses/by/4.0/

(c) (i) Open Access

\section{Abstract}

Purpose: This study reports the reliability and validity analyses of the Audit on diabetes-dependent quality of life (ADDQoL) and EQ-5D in elderly Slovenian diabetic patients. Methods: A crosssectional study of elderly (age $\geq 65$ years) non-insulin dependent diabetes mellitus type 2 (DMT2) patients was carried out. The ADDQoL and EQ-5D surveys were conducted between January and May, 2012. Statistical analysis was performed using IBM SPSS Statistics software, version 20.0. Results: After exclusion of non-eligible respondents, the final sample for the analysis was 261 cases (51\% male), resulting in $\mathbf{5 2 . 2 \%}$ of response rate. The mean age of the patients was 70.3 years (SD \pm 4.1). The Cronbach's alpha was 0.93 for ADDQoL and 0.73 for EQ-5D.There was no improvement in the alpha value if any item was deleted in all instruments. Missing value items ranged from $0.8 \%$ to $\mathbf{1 . 5 \%}$ for EQ-5D, and from $\mathbf{0 . 8 \%}$ to $\mathbf{5 9 . 1 \%}$ (working life) in ADDQoL. Spearman's correlation between the EQ-5D VAS score and ADDQoL weighted overall score resulted in weak correlations coefficient ( $r=0.294 ; p<0.001)$. Conclusions: The ADDQoL proved reliable and valid for assessing Health Related Quality of Life (HRQoL) among elderly Slovenian DMT2 patients. EQ-5D seemed to be too generic to describe limitations of DMT2 patients in detail. Using disease specific QoL instruments to learn about patient limitations was recommended. Comparison of ADDQoL results between various studies provided significant differences in the impact of diabetes.

${ }^{*}$ Corresponding author. 


\section{Keywords}

\section{DMT2; Elderly; Patient Reported Outcomes; ADDQoL; EQ-5D; Health Related Quality of Life}

\section{Introduction}

Diabetes mellitus type 2 (DMT2) is one of the most common chronic diseases globally. DMT2 is also psychologically demanding. It can significantly impair the patient's health-related quality of life (HRQoL), particularly if the patient has other chronic conditions [1]-[3]. In 2010, there were 285 million people affected by diabetes [4]. The 2010 OECD report [5] stated that diabetes was the main cause of death of more than 100,000 people in EU countries in 2008, and in most developed countries it was in the top five leading causes of death. Hence, diabetes is an important health concern in high income countries.

In Slovenia, the number of diabetic patients is growing and estimated to be approximately 125,000 adults (20 to 79 years) [6]. As a result, reducing the number of diabetic patients has been put higher in the health policy agenda especially because of the rising incidence and prevalence of DMT2 as a result of negative lifestyle developments (e.g. obesity). This is evident in the establishment of The National Diabetes Prevention and Care Development Programme 2010-2020 [7]. This Programme represents the strategic foundation for taking measures in the area of prevention, early detection and treatment of diabetes mellitus, as well as for monitoring, researching and educating. In addition, diabetes makes social care and economic issues more challenging for the society, as it is one of the diseases that are fully reimbursed by the compulsory health insurance. To better inform patient management and medical decision making, a better understanding of the psychosocial burden of diabetes is required.

In the past two decades, HRQoL as a patient reported outcome (PRO) has gained its importance in health care [8]. This is because HRQoL encompasses physical, psychological and social aspects of diabetic patients. There is a growing interest in literature and medical practices to assess chronic diseases (e.g. diabetes) in relation to their impacts on quality of life (QoL) in addition to medical outcomes (e.g. morbidity and mortality) [9]-[11]. Many studies support the use of HRQoL as a measure because subjective health is perceived as a better predictor of survival than objective health [12]. In addition, associations between chronic diseases and lower levels of HRQoL are evident. This is because if a chronic patient is to be better, the patient will need to change his or her lifestyle significantly [13] [14]. Thus, the measurement of HRQoL is an important activity.

There are several questionnaires created to measure HRQoL in diabetic patients, including generic instruments (e.g. EQ-5D) and disease-specific questionnaires (e.g. ADDQoL) [15]-[17]. However, no diabetes specific HRQoL measurements have been validated in Slovenia. It is crucial to validate a questionnaire specifically for Slovenia because lifestyles vary between countries and cultures, and these differences directly affect how a society perceives a high quality life. Another reason is that it is important to re-validate a translated questionnaire.

The aim of this study was to evaluate the reliability and validity of the Slovenian ADDQoL version in the diabetic population. Due to the lack of other diabetes specific questionnaires, the results of the ADDQol were compared to a generic questionnaire. Specifically, the EuroQol group questionnaire with five dimensions (EQ-5D), which was previously translated and culturally adapted for Slovenian population [18]-[20], was used as a comparison. In addition, a benchmark with other published studies was conducted to identify whether diabetes has a similarly negative impact on the QoL.

\section{Methods}

\subsection{Instruments}

The Audit on diabetes-dependent quality of life (ADDQoL) assesses the impact of diabetes on 19 life domains. It consists of two overview items: (1) one measures generic overall quality of life and (2) another one measures the specific impact of diabetes on quality of life.

The 19 life domains can be rated from -3 to +1 (called 'impact ratings') and from 0 to +3 in attributed importance (called 'importance ratings') [3] [8] [21]. Finally, an average weighted impact score (AWI) is calculated for the entire scale, as a multiplier of impact rating and importance rating (range from -9 to 3). 
The EQ-5D is a health status instrument that is standardized, validated, generic, preference-based, and has been translated into more than 25 languages including Slovene [18] [22] [23]. It describes the participants' health state on five dimensions: mobility, self-care, usual activities, pain/discomfort and anxiety/depression. Each of these dimensions is split into three levels, generating 243 possible health states, each of which is associated with a utility score (range -0.59 to 1 ) [23] [24].

\subsection{Linguistic Validation of ADDQoL}

After obtaining the developers' authorization, the ADDQoL was translated from the source English (UK) into Slovenian version using a standardized methodology of forward and back translation. The linguistic validation process is shown in Figure 1.

The forward translation (FT) was conducted independently by two Slovene translators, both fluent in English. The initial translation was subject for discussion, and once a consensus was reached among the project manager and translators, the first version of ADDQoL in Slovene was ready. After the FT, two other bilingual translators were recruited to back translate (BT) the ADDQoL into English independently. Following the final reconciliation, a BT report was compiled and sent to the developer. After revision and discussion with the developer, a preliminary ADDQoL was reconciled. This preliminary ADDQoL was subject to clinical and psychological reviews, which were carried out separately, by a medical specialist in diabetology and a public health psychologist, and a report was submitted after their review.

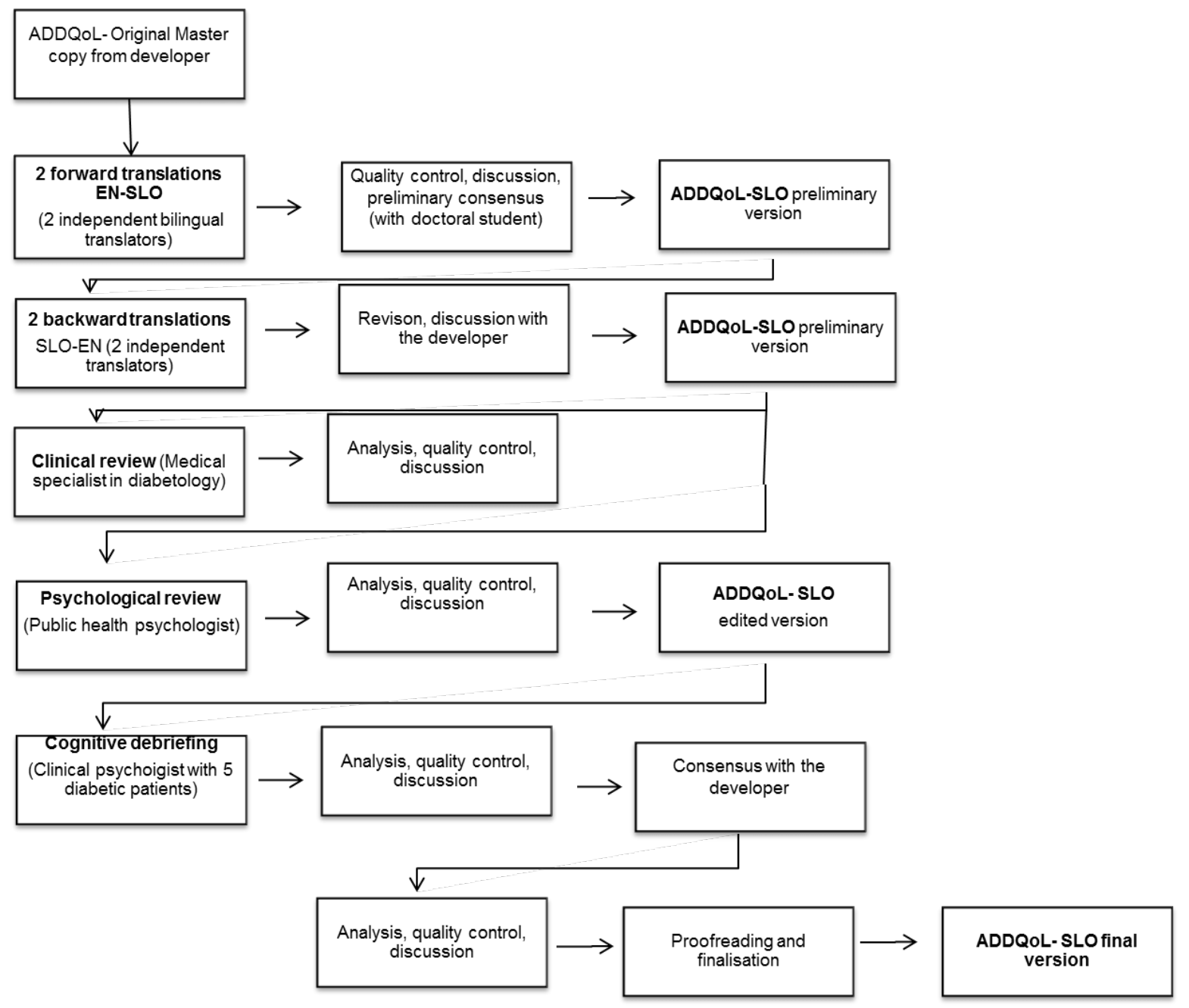

Figure 1. ADDQoL linguistic validation process. 
Once the consensus with the developer was reached, cognitive debriefing was conducted. During the interview with a clinical psychologist, five patients (various age, sex, education and type of diabetes) were asked about their view of health and QoL, and relevance of each item to themselves. In addition, the participants were asked about possible difficulties in understanding the items. Results were generated into the cognitive debriefing report. The edited version of the ADDQoL was produced and subjected to reconciliation. After several rounds of reconciliation, the approval was obtained, and the final Slovenian version of the ADDQoL was produced.

The Slovenian EQ-5D instrument used for the current study was validated previously [18] [25].

\subsection{Study Design and Data Collection}

A cross-sectional research design was applied using a structured questionnaire. The study was conducted between January and May 2012. After obtaining the ethics approval from the National Medical Ethics Committee of the Republic of Slovenia, outpatient diabetic centers were asked to recruit patients for the study. For recruitment we used the largest outpatient center in each region of Slovenia; thus providing 12 outpatient diabetic centers for the study. Each outpatient center recruited 20 to 80 patients depending on the region size and prevalence [26]. Patients were eligible to participate in the study if they had been diagnosed DMT2, without insulin therapy, and had been aged 65 years or older. Patients with Type 1 diabetes, secondary diabetes or gestational diabetes were excluded from the study. After obtaining the informed consent, participants were handed out the questionnaire. Because the participants were elderly people, assistance in filling in the questionnaire was provided by medical students who were specially trained for the ADDQoL questionnaire prior to the data collection.

\subsection{Sample Breakdown}

Five hundred elderly people were asked to participate in the study, in which $78.2 \%(n=391)$ agreed. Considering participants' age and possible life development tasks, the ADDQoL items "working life" and "sex life" were omitted from the analysis. There were some cases excluded from analysis because the following ADDQoL items received a very low response rate: 107 (21.4\%) cases of the item "holidays", 28 (4.6\%) cases of the item "personal relationship", and the item "financial situation" (0.2\%). Although all items from ADDQoL and EQ-5D had at least one missing value, there was no need to exclude further cases because missing values were the combination of two items: a) "holidays" or b) "personal relationship". The final sample for the analysis was 261 cases (52.2\% of response rate).

\subsection{Data Analysis}

The sample data were expressed as frequencies and percentages for categorical variables or by mean values and standard deviations $(\mathrm{M} \pm \mathrm{SD})$ for continuous variables. Factor analysis (PAF-principal axis factoring) was calculated with Varimax rotation and eigenvalues $>1$. An international comparison was made using one-way ANOVA. Statistical analysis was performed with the IBM SPSS 20.0 software (IBM Corp., Armonk, NY). P < 0.05 was considered as statistically significant.

\section{Results}

\subsection{Patient Characteristics}

A total of 261 elderly DMT2 patients responded to the questionnaire, in which 51\% were male. The mean age of the patients was 70.3 years $(\mathrm{SD} \pm 4.1$ ). The patient characteristics are presented in Table 1 .

EQ-5D results are presented in Table 2 . Approximately $50 \%$ of participants reported some health problems in mobility and pain/discomfort. EQ-5D VAS score was calculated at $0.66 \pm 0.12$ (range: 0.05 - 0.77).

ADDQoL results are presented in Table 3. Participants omitted "sex life" and "working life" domains. The lowest mean weighted impact score (major concern) was calculated in "freedom to eat" (-3.2, SD 2.9) and the highest mean weighted impact score (minorconcern) was calculated in "people's reaction" domain $(-0.8, \mathrm{SD}$ 1.6).

\subsection{Reliability and Feasibility}

For EQ-5D instrument Cronbach's alpha was 0.73, and there was no improvement in alpha value if any item 
Table 1. Sample description.

\begin{tabular}{|c|c|c|}
\hline & $\mathrm{n}=261$ & $\%$ \\
\hline \multicolumn{3}{|l|}{ Gender } \\
\hline Male & 133 & 51.0 \\
\hline Female & 128 & 49.0 \\
\hline \multicolumn{3}{|l|}{ Education } \\
\hline Primary education & 77 & 29.5 \\
\hline Secondary education & 154 & 59.0 \\
\hline College or higher & 30 & 11.5 \\
\hline \multicolumn{3}{|l|}{ Marital status } \\
\hline Married, in partnership & 176 & 67.4 \\
\hline Widowed & 64 & 24.5 \\
\hline Divorced & 10 & 3.8 \\
\hline Single & 11 & 4.2 \\
\hline \multicolumn{3}{|l|}{ Residence } \\
\hline Own house & 159 & 60.9 \\
\hline Own Apartment & 83 & 31.8 \\
\hline Renting & 9 & 3.4 \\
\hline Relatives & 7 & 2.7 \\
\hline Nursing home & 3 & 1.1 \\
\hline \multicolumn{3}{|l|}{ Monthly income in EUR } \\
\hline 365 or less & 32 & 12.3 \\
\hline 366 to 730 & 151 & 57.9 \\
\hline 731 to 1100 & 53 & 20.3 \\
\hline 1101 or above & 25 & 9.6 \\
\hline \multicolumn{3}{|l|}{ Region } \\
\hline$\leq 200$ per $\mathrm{km}^{2}$ (rural) & 39 & 14.9 \\
\hline$>200$ per km² (urban) & 222 & 85.1 \\
\hline Age in years $(\mathrm{M} \pm \mathrm{SD}$, range) & $70.3 \pm 4.1$ & $65-84$ \\
\hline
\end{tabular}

M: mean, SD: standard deviation.

Table 2. Self evaluated health status in EQ-5D $(n=261)$.

\begin{tabular}{cccc}
\hline & Mean score $(\mathrm{M} \pm \mathrm{SD})$ & $\begin{array}{c}\text { Proportion of at least some } \\
\text { health problems (\%) }\end{array}$ & $\begin{array}{c}\text { Proportion with severe } \\
\text { health problems (\%) }\end{array}$ \\
\hline EQ-5D & & & \\
Mobility & $1.53 \pm 0.51$ & 51.5 & 0.7 \\
Self-care & $1.16 \pm 0.41$ & 12.4 & 1.7 \\
Usual activities & $1.30 \pm 0.49$ & 27.8 & 4.3 \\
Pain/discomfort & $1.57 \pm 0.57$ & 49.2 & 4.0 \\
Anxiety/depression & $1.40 \pm 0.57$ & 30.9 & 4.4 \\
\hline
\end{tabular}


Table 3. Distribution of ADDQoL responses by impact and importance rating together with the weighted impact score, ranks and zero importance ratings.

\begin{tabular}{|c|c|c|c|c|c|c|c|c|c|}
\hline \multirow[t]{2}{*}{ Domain } & \multirow[t]{2}{*}{$\begin{array}{c}\text { NA response (\%) } \\
n=391\end{array}$} & \multicolumn{2}{|c|}{$\begin{array}{c}\text { Impact rating } \\
\mathrm{n}=261\end{array}$} & \multicolumn{2}{|c|}{$\begin{array}{l}\text { Importance rating } \\
\qquad \mathrm{n}=261\end{array}$} & \multicolumn{2}{|c|}{$\begin{array}{c}\text { Weighted } \\
\text { impact score } \\
\text { n = 261 }\end{array}$} & \multirow[t]{2}{*}{$\begin{array}{l}\operatorname{Rank}^{* *} \\
\mathrm{n}=261\end{array}$} & \multirow{2}{*}{$\begin{array}{c}\text { Zero } \\
\text { importance ratings } \\
\mathrm{n}=261 \\
\mathrm{n}(\%)\end{array}$} \\
\hline & & M & SD & M & $\mathrm{SD}$ & M & SD & & \\
\hline Leisure activities & & -1.1 & 1.0 & 1.9 & 0.7 & -2.2 & 2.2 & 6 & 47 (18.0\%) \\
\hline Working life ${ }^{*}$ & $231(59.1)$ & & & & & & & & \\
\hline Journeys & & -1.3 & 1.0 & 1.8 & 0.8 & -2.5 & 2.5 & 2 & $24(9.2 \%)$ \\
\hline Holidays & $107(27.4)$ & -1.1 & 1.0 & 1.8 & 0.8 & -2.0 & 2.2 & 7 & $15(5.7 \%)$ \\
\hline Physical health & & -1.2 & 1.0 & 1.9 & 0.7 & -2.5 & 2.4 & 2 & 9 (3.4\%) \\
\hline Family life & $13(3.3)$ & -0.9 & 0.9 & 2.4 & 0.6 & -2.4 & 2.5 & 5 & $1(0.4 \%)$ \\
\hline Friendship and social life & & -0.9 & 1.0 & 2.0 & 0.8 & -1.9 & 2.5 & 11 & $8(3.1 \%)$ \\
\hline Personal relationship & $81(20.7)$ & -0.8 & 1.0 & 2.3 & 0.7 & -2.0 & 2.5 & 7 & $5(1.9 \%)$ \\
\hline Sex life ${ }^{*}$ & $144(36.8)$ & & & & & & & & \\
\hline Physical appearance & & -0.7 & 0.9 & 1.5 & 0.9 & -1.4 & 2.1 & 16 & $36(13.8 \%)$ \\
\hline Self-confidence & & -0.8 & 1.0 & 2.0 & 0.7 & -1.8 & 2.4 & 13 & $9(3.4 \%)$ \\
\hline Motivation & & -0.9 & 1.0 & 1.9 & 0.7 & -1.9 & 2.5 & 11 & $10(3.8 \%)$ \\
\hline People's reaction & & -0.4 & 0.7 & 1.5 & 0.9 & -0.8 & 1.6 & 18 & $51(19.5 \%)$ \\
\hline Feelings about future & & -1.1 & 1.0 & 1.9 & 0.7 & -2.5 & 2.5 & 2 & $14(5.4 \%)$ \\
\hline Financial situation & & -0.6 & 0.9 & 2.0 & 0.7 & -1.3 & 2.2 & 17 & 9 (3.4\%) \\
\hline Living conditions & & -0.9 & 0.9 & 2.1 & 0.7 & -2.0 & 2.5 & 7 & $4(1.5 \%)$ \\
\hline Dependence on others & & -0.6 & 0.9 & 2.5 & 0.7 & -1.5 & 2.4 & 15 & 5 (1.9\%) \\
\hline Freedom to eat & & -1.5 & 1.0 & 1.8 & 0.9 & -3.2 & 2.9 & 1 & $22(8.4 \%)$ \\
\hline Freedom to drink & & -0.9 & 1.0 & 1.2 & 1.0 & -1.6 & 2.3 & 14 & $94(36.0 \%)$ \\
\hline
\end{tabular}

M: mean, SD: standard deviation, NA: not available. * due to elderly population item was less considered and was omitted from further analysis. ${ }^{* *} 1$ being the greatest impact; items with the same mean weighted impact scores have the same rank.

was deleted. Corrected item to total correlation coefficients ranged between 0.39 and 0.53 . The mean inter-item correlation coefficients ranged from 0.29 to 0.38 , the lowest was 0.25 (usual activities vs. anxiety/depression). The strongest correlation coefficient was 0.58 between self-care and usual activities. Seventy percent of inter-items correlations were between 0.30 and 0.70 (moderate correlation).

For ADDQoL instrument Cronbach's alpha was 0.93, there was no improvement in alpha value if any item was deleted. Corrected item to total correlation coefficients ranged between 0.19 and 0.80 . Item "freedom to drink" was the only one that did not meet the correction value of over 0.30 . The mean inter-item correlation coefficients ranged from 0.13 to 0.54 , the lowest was $<0.01$ (people's reaction vs. freedom to drink). The strongest correlation coefficient was 0.79 between self-confidence and motivation. Moderate inter-items correlation ( 0.30 $<\mathrm{r}<0.70$ ) coefficients were conducted in $80.9 \%$ of cases.

Missing values for EQ-5D items ranged from $0.8 \%$ to $1.5 \%$, most for anxiety/depression items. Missing values for ADDQoL ranged from $0.8 \%$ to $59.1 \%$ (working life). Due to elderly population two items were of less interest: "working life" and "sex life". After exclusion of these two items, missing values were recorded from $0.8 \%$ (freedom to drink) to $27.4 \%$ (holidays). Table 4 presents the missing data and reliability coefficients for the two instruments.

\subsection{Construct Validity}

Construct validity was examined by principal axis factoring. Kaiser-Meyer-Olkin measure of sampling ade- 
Table 4. EQ-5D and ADDQoL reliability and feasibility.

\begin{tabular}{|c|c|c|c|c|}
\hline Instrument & $\begin{array}{l}\text { Missing data } \\
\mathrm{n}=391(\%)\end{array}$ & $\begin{array}{l}\text { Internal consistency } \\
\text { (Cronbach’s } \alpha \text { ) } \\
\mathrm{n}=261\end{array}$ & $\begin{array}{c}\text { Corrected } \\
\text { item-total } \\
\text { correlation } \\
n=261\end{array}$ & $\begin{array}{c}\text { inter-item } \\
\text { correlation } \\
\text { (lowest, mean) } \\
\mathrm{n}=261\end{array}$ \\
\hline EQ-5D & & 0.73 & & \\
\hline Mobility & $3(0.8)$ & $0.67^{\#}$ & 0.53 & $0.27,0.38$ \\
\hline Self-care & $3(0.8)$ & $0.68^{\#}$ & 0.53 & $0.29,0.39$ \\
\hline Usual activities & $3(0.8)$ & $0.68^{\#}$ & 0.52 & $0.25,0.39$ \\
\hline Pain/discomfort & $5(1.3)$ & $0.67^{\#}$ & 0.53 & $0.35,0.38$ \\
\hline Anxiety/depression & $6(1.5)$ & $0.73^{\#}$ & 0.39 & $0.25,0.29$ \\
\hline ADDQoL $^{* *}$ & & 0.93 & & \\
\hline Leisure activities & $9(2.3)$ & $0.92^{\#}$ & 0.62 & $0.09,0.43$ \\
\hline Working life ${ }^{*}$ & $231(59.1)$ & & & \\
\hline Journeys & $9(2.3)$ & $0.92^{\#}$ & 0.64 & $0.00,0.45$ \\
\hline Holidays & $107(27.4)$ & $0.92^{\#}$ & 0.61 & $0.13,0.42$ \\
\hline Physical health & $12(3.1)$ & $0.92^{\#}$ & 0.64 & $-0.05,0.44$ \\
\hline Family life & $13(3.3)$ & $0.92^{\#}$ & 0.69 & $0.17,0.47$ \\
\hline Friendship and social life & $8(2.0)$ & $0.92^{\#}$ & 0.77 & $0.08,0.53$ \\
\hline Personal relationship & $81(20.7)$ & $0.92^{\#}$ & 0.71 & $0.09,0.49$ \\
\hline Sex life ${ }^{*}$ & $144(36.8)$ & & & \\
\hline Physical appearance & $13(3.3)$ & $0.92^{\#}$ & 0.75 & $0.11,0.51$ \\
\hline Self-confidence & $9(2.3)$ & $0.92^{\#}$ & 0.80 & $0.10,0.54$ \\
\hline Motivation & $8(2.0)$ & $0.92^{\#}$ & 0.73 & $0.22,0.50$ \\
\hline People's reaction & $9(2.3)$ & $0.93^{\#}$ & 0.53 & $0.01,0.37$ \\
\hline Feelings about future & $9(2.3)$ & $0.92^{\#}$ & 0.67 & $0.22,0.45$ \\
\hline Financial situation & $11(2.8)$ & $0.92^{\#}$ & 0.64 & $0.10,0.44$ \\
\hline Living conditions & $10(2.6)$ & $0.92^{\#}$ & 0.73 & $0.16,0.49$ \\
\hline Dependence on others & $9(2.3)$ & $0.92^{\#}$ & 0.61 & $0.05,0.43$ \\
\hline Freedom to eat & $7(1.8)$ & $0.93^{\#}$ & 0.49 & $0.12,0.33$ \\
\hline Freedom to drink & $3(0.8)$ & $0.93^{\#}$ & 0.19 & $-0.05,0.13$ \\
\hline
\end{tabular}

*item was less considered and omitted from analysis. ${ }^{*}$ Cronbach's $\alpha$ if item was deleted. ${ }^{* *}$ ADDQoL weighted scores.

quacy for EQ-5D was 0.731 and Bartlett's Test of Sphericity $\left(X^{2}=328.453, d f=10, p<0.001\right)$, both indicated that the assumption criterion was met for the factor analysis.

Kaiser-Meyer-Olkin measure of sampling adequacy for ADDQoL was 0.908 and Bartlett's Test of Sphericity $\left(\mathrm{X}^{2}=1378.622, \mathrm{df}=136, \mathrm{p}<0.001\right)$, both indicated that the assumption criterion was met for the factor analysis.

Table 5 shows the factor analysis of the questionnaires. For EQ-5D all items loaded to the same one-factor solution, explaining $49.5 \%$ of total variance. For ADDQoL all items loaded above 0.4 to the first factor, but "freedom to drink". Item "freedom to drink" loaded to the second factor and item "leisure activities" loaded to the third factor. A non-rotated three-factor solution explained $64.3 \%$ of total variance. In the forced one-factor solution for ADDQoL all items but "freedom to drink" had factor loadings of $>0.4$. Freedom to drink loaded 
Table 5. Factor analysis of EQ-5D and ADDQoL items $(n=261)$.

\begin{tabular}{|c|c|c|c|c|}
\hline Instrument & Factor 1 & Factor 2 & Factor 3 & $\begin{array}{l}\text { Total variance } \\
\text { explained (\%) }\end{array}$ \\
\hline EQ-5D & & & & 49.5 \\
\hline Mobility & 0.727 & & & \\
\hline Self-care & 0.740 & & & \\
\hline Usual activities & 0.745 & & & \\
\hline Pain/discomfort & 0.718 & & & \\
\hline Anxiety/depression & 0.575 & & & \\
\hline ADDQoL $^{* *}$ & & & & 64.3 \\
\hline Leisure activities & 0.673 & & 0.401 & \\
\hline \multicolumn{5}{|l|}{ Working life ${ }^{*}$} \\
\hline Journeys & 0.707 & & & \\
\hline Holidays & 0.656 & & & \\
\hline Physical health & 0.705 & & & \\
\hline Family life & 0.732 & & & \\
\hline Friendship and social life & 0.824 & & & \\
\hline Personal relationship & 0.762 & & & \\
\hline \multicolumn{5}{|l|}{ Sex life ${ }^{*}$} \\
\hline Physical appearance & 0.798 & & & \\
\hline Self-confidence & 0.843 & & & \\
\hline Motivation & 0.776 & & & \\
\hline People’s reaction & 0.598 & & & \\
\hline Feelings about future & 0.701 & & & \\
\hline Financial situation & 0.696 & & & \\
\hline Living conditions & 0.768 & & & \\
\hline Dependence on others & 0.680 & & & \\
\hline Freedom to eat & 0.500 & & & \\
\hline Freedom to drink & & 0.806 & & \\
\hline
\end{tabular}

"due to elderly population item was less considered and was omitted from further analysis. ${ }^{* *}$ ADDQoL weighted scores.

with a value of 0.188 into this factor. The forced one-factor solution explained $48.8 \%$ of total variance.

Twelve studies involving ADDQoL were considered for statistical comparisons to Slovenian results. The results were presented in a comparable manner in four studies [27]-[30]. For example, Zhang et al. [31] made a comparison between English and Chinese speaking populations, although did not provide results for the entire sample. Chung et al. [32] provided median values with interquartile range. While some studies [21] [33] provided only graphical results, others [34] [35] provided only summarised scores which were used for further statistical analyses. Lemon and Rosal [36] and Demirci et al. [37] used modified/simplified ADDQoL, therefore some domains were not completely comparable. The international comparison of the relevant studies is presented in Table 6.

\section{Discussion}

Patient reported outcome measurements (PROMs), particularly HRQoL, present an important component in 
Table 6. International comparison of ADDQoL domains.

\begin{tabular}{|c|c|c|c|c|c|c|c|c|c|c|c|}
\hline & \multicolumn{2}{|c|}{$\begin{array}{l}\text { Present study } \\
\text { Slovenia } \\
\text { n=261 }\end{array}$} & \multicolumn{2}{|c|}{$\begin{array}{c}\text { Soon et al. (2010) } \\
\text { Singapore } \\
\mathrm{n}=88\end{array}$} & \multicolumn{2}{|c|}{$\begin{array}{c}\text { Kong et al. (2011) } \\
\text { China } \\
\mathrm{n}=697\end{array}$} & \multicolumn{2}{|c|}{$\begin{array}{l}\text { Wee et al. (2006) } \\
\text { China, India } \\
\text { n = } 152\end{array}$} & \multicolumn{2}{|c|}{$\begin{array}{c}\text { Holmanova and } \\
\text { Ziakova (2008) } \\
\text { Slovakia } \\
n=104\end{array}$} & \multirow[t]{2}{*}{$\mathrm{p}$} \\
\hline & M & $\mathrm{SD}$ & M & $\mathrm{SD}$ & M & SD & M & $\mathrm{SD}$ & M & SD & \\
\hline Leisure activities & -2.2 & 2.2 & -2.4 & 2.8 & -1.9 & 1.9 & -3.5 & 3.0 & -3.1 & 3.0 & $<0.001$ \\
\hline Working life ${ }^{*}$ & & & -3.5 & 2.9 & -1.7 & 2.4 & -4.4 & 3.0 & -3.8 & 3.2 & I \\
\hline Journeys & -2.5 & 2.5 & -2.6 & 2.7 & -2.1 & 2.1 & -3.3 & 2.9 & -3.3 & 3.0 & $<0.001$ \\
\hline Holidays $^{* *}$ & -2.0 & 2.2 & -2.5 & 2.7 & -1.7 & 2.3 & -3.5 & 3.3 & -2.9 & 3.1 & $<0.001$ \\
\hline Physical health & -2.5 & 2.4 & -2.5 & 2.6 & -2.1 & 1.9 & -4.5 & 3.0 & -3.9 & 3.0 & $<0.001$ \\
\hline Family life $^{* *}$ & -2.4 & 2.5 & -3.3 & 2.9 & -3.4 & 2.6 & -5.1 & 3.1 & -3.7 & 3.2 & $<0.001$ \\
\hline Friendship and social life & -1.9 & 2.5 & -2.4 & 2.6 & -2.5 & 2.3 & -3.6 & 3.0 & -2.6 & 3.2 & $<0.001$ \\
\hline Personal relationship ${ }^{* *}$ & -2.0 & 2.5 & -2.8 & 2.9 & -2.7 & 2.6 & -4.5 & 3.0 & -2.7 & 3.1 & $<0.001$ \\
\hline Sex life ${ }^{*}$ & & & -2.7 & 2.8 & -1.6 & 2.4 & -3.7 & 3.1 & -2.6 & 3.0 & I \\
\hline Physical appearance & -1.4 & 2.1 & -2.3 & 2.7 & -2.7 & 2.2 & -3.3 & 3.1 & -2.4 & 2.9 & $<0.001$ \\
\hline Self-confidence & -1.8 & 2.4 & -3.3 & 2.8 & -3.4 & 2.4 & -4.2 & 2.9 & -2.8 & 3.1 & $<0.001$ \\
\hline Motivation & -1.9 & 2.5 & -3.2 & 3.0 & -3.2 & 2.3 & -3.7 & 3.2 & -3.3 & 3.1 & $<0.001$ \\
\hline People’s reaction & -0.8 & 1.6 & -1.5 & 2.2 & -1.9 & 2.2 & -2.7 & 3.0 & -1.6 & 2.5 & $<0.001$ \\
\hline Feelings about future & -2.5 & 2.5 & -3.7 & 3.2 & -3.0 & 2.2 & -4.9 & 3.0 & -3.9 & 3.1 & $<0.001$ \\
\hline Financial situation & -1.3 & 2.2 & -3.6 & 3.1 & -3.6 & 2.3 & -4.1 & 3.2 & -4.2 & 3.5 & $<0.001$ \\
\hline Living conditions & -2.0 & 2.5 & -3.8 & 3.0 & -3.2 & 2.1 & -4.2 & 3.3 & -2.5 & 3.1 & $<0.001$ \\
\hline Dependence on others & -1.5 & 2.4 & -1.7 & 2.4 & -2.3 & 2.1 & -3.1 & 3.4 & -2.6 & 3.1 & $<0.001$ \\
\hline Freedom to eat & -3.2 & 2.9 & -3.9 & 3.3 & -2.9 & 2.1 & -5.5 & 3.2 & -4.3 & 3.2 & $<0.001$ \\
\hline Freedom to drink & -1.6 & 2.3 & -3.1 & 3.2 & -2.0 & 1.9 & -3.9 & 3.0 & -3.1 & 3.2 & $<0.001$ \\
\hline
\end{tabular}

${ }^{*} \mathrm{p}$ was not calculated because NA response was too high(/). ${ }^{* *}$ reduced sample due NA response was considered.

continuous improvement of chronic disease management [38]. A number of instruments for measuring HRQoL have been developed and used across chronic diseases including DMT2. In this study, the diabetes specific questionnaire ADDQoL was translated from the source English (UK) version into Slovene. The aim of the study was to evaluate the ADDQoL and the generic EQ-5D in terms of reliability, validity and feasibility among elderly DMT2 patients in Slovenia.

Similar to other studies [17] [27] [39], our findings show that both instruments seem reliable. Results of factor analysis, the Cronbach's alpha index, showed satisfactory results in multiple aspects of the ADDQoL scale, implying that the items were well translated and culturally adapted for Slovenian population (age 65 years or older).

The greatest negative weighted impact observed was consistent with previous studies [3] [27] [30] and the international comparison. The domain "freedom to eat", indicates a strong influence of dietary restrictions on QoL, bearing in mind that overweight is one of the most important factors contributing to the development of DMT2. It was thus not surprising that "freedom to eat" ranked as the first on the list. Domain "freedom to eat" had also the maximum negative unweighted impact score, yet it was not dramatically enhanced by the importance rating. Highest importance rating was reported for "family life", "personal relationship" and "dependence on others". These can be interpreted that Slovenian elderly people highly value family ties and personal relationships, yet 
they are afraid to get dependent in activities of daily living and in need to ask loved ones to provide help or to move to nursing home. Other studies [17] [27] [28] [30] provided a similar picture regarding "family life" and "personal relationships" but not regarding "dependence on others". We believe that the latter finding may be connected the fact that our participants were elderly.

Our experience in collecting the data shows that only a few participants reported difficulties in filling in the questionnaire. However, there were still some missing responses. The items "working life" and "sex life" in the ADDQoL had the highest missing data. The missing responses for "working life" is understandable because most of the participants in the study were retired, thus the working life had not been a major concern for them. The missing responses for the item "sex life" may be explained by the fact that most elderly people do not usually discuss sexuality-related topics with their doctors [40] or openly with others. In addition, the study by Robinson and Molzahn [41] shows that elderly people who reported higher satisfaction with personal relationships also reported higher ratings of QoL than those who reported lower satisfaction.

Comparisons of ADDQoL results between various studies provided significant differences in the impact of diabetes. This may lead to the conclusion that it is important to consider the severity of the disease. For example, Holmanova and Ziakova [27] included patients with intensified insulin therapy and results provided a higher negative disease impact. Similarly, Wee et al. [42] included DMT1 and DMT2 patients, and found that those who required insulin therapy (35\%) reported worsened ADDQoL scores. Soon et al. [28] included DMT2 patients, of whom $44 \%$ reported using the insulin therapy. Kong et al. [17] included DMT2 patients only, without providing the number of patients using the insulin therapy. Slovenian sample included non-insulin DMT2 patients; this study and Kong et al. [17] reported lower diabetes impact on QoL when compared to first ones cited [27] [28] [30] in this paragraph. Inconsistency of findings may be related to age differences among various samples, in which the Slovenian sample, with the oldest participants (mean age was above 70 years), reported a lower diabetes impact. Kong et al. [17] reported the second largest impact with second largest mean age of 59 years. Studies which reported a higher impact on QoL included younger participants (mean age from 46 to 57 years). This may suggest that an elderly population is less impacted by diabetes. Some studies found that elderly people reported a higher life satisfaction compared to that of middle-aged people [43] [44].

EQ-5D as a generic health score was found to have a weak correlation with the disease specific ADDQoL score, which was similar to the findings in Soon et al. [28]. This may conclude that EQ-5D is too generic to describe limitations of DMT2 patients in detail. Using diseases specific QoL instruments to learn about patient limitations is thus recommended.

\subsection{Recommendations for Future Research}

ADDQoL instrument is frequently used as a diabetes specific QoL instrument internationally. However, results are difficult to compare, because, for example, some studies provided graphical results only, whereas other sonly used interquartile ranges or summarised scores. In addition, some studies have adapted ADDQoL to fit their study populations better and thus it is difficult to make a comparison. If ADDQoL is to be promoted, results should be published as originally suggested, which is by showing the importance rating, impact rating and weighted impact score. In case of unexpected deviations, an explanation should be provided on why some domains were inappropriate for the targeted population. This may lead give a better understanding on how the QoL is influenced by the severity of the disease and age.

\subsection{Study Limitations}

We recognize that there are limitations in our study. First, the generalizability of our findings to the general population with DMT2 may be limited because of the lack of randomized sampling and the use of a convenience sampling. A larger sample would provide more statistical power to detect significant associations between the study variables and the differences between groups.

\section{Conclusion}

We have demonstrated that the ADDQoL is culturally appropriate, valid and reliable to measure DMT2 elderly patients in Slovenia. The questionnaire was relatively easy to fill in by elderly patients. An international com- 
parison of results however was difficult because results might be influenced by the severity of the disease and age.

\section{Acknowledgements}

The authors would like to thank Jelka Zaletel, MD, PhD for her suggestions and advice. We gratefully acknowledge the outpatient diabetic centers, the health professionals and the diabetic patients in the regions for their willingness to participate in the study. Furthermore, the authors greatly acknowledge the contribution of Rosalind Plowright and Prof. Clare Bradley for their advice and support during the linguistic validation.

\section{Conflict of Interest}

There are no conflicts of interest.

\section{References}

[1] Garratt, A., Schmidt, L. and Fitzpatrick, R. (2002) Patient Assessed Health Outcome Measures for Diabetes: A Structured Review. Diabetic Medicine, 19, 1-11. http://dx.doi.org/10.1046/j.1464-5491.2002.00650.x

[2] Cox, W.M., Blount, J.P., Crowe, P.A. and Singh, S.P. (1996) Diabetic Patients’ Alcohol Use and Quality of Life: Relationships with Prescribed Treatment Compliance among Older Males. Alcoholism: Clinical and Experimental Research, 20, 327-331. http://dx.doi.org/10.1111/j.1530-0277.1996.tb01647.x

[3] Bradley, C. and Speight, J. (2002) Patient Perceptions of Diabetes and Diabetes Therapy: Assessing Quality of Life. Diabetes/Metabolism Research and Reviews, 18, S64-S69. http://dx.doi.org/10.1002/dmrr.279

[4] International Diabetes Federation (2009) IDF Diabetes Atlas. Brussels: International Diabetes Federation.

[5] Organisation for Economic Co-Operation and Development (2010) Health at a Glance: Europe 2010.

[6] International Diabetes Federation (2012) IDF Diabetes Atlas.

[7] Ministry of Health (2010) Nacionalni Program za Obvladovanje Sladkorne Bolezni. Strategija Razvoja 2010-2020. Ljubljana.

[8] Bradley, C., Todd, C., Gorton, T., Symonds, E., Martin, A. and Plowright, R. (1999) The Development of an Individualized Questionnaire Measure of Perceived Impact of Diabetes on Quality of Life: The ADDQoL. Quality of Life Research, 8, 79-91. http://dx.doi.org/10.1023/A:1026485130100

[9] Akinci, F., Yildirim, A., Gözü, H., Sargın, H., Orbay, E. and Sargın, M. (2008) Assessment of Health-Related Quality of Life (HRQoL) of Patients with Type 2 Diabetes in Turkey. Diabetes Research and Clinical Practice, 79, 117-123. http://dx.doi.org/10.1016/j.diabres.2007.07.003

[10] Devlin, N.J. and Appleby, J. (2010) Getting the Most out of PROMs. Kings Fund, London.

[11] Devlin, N.J., Parkin, D. and Browne, J. (2010) Patient Reported Outcome Measures in the NHS: New Methods for Analysing and Reporting EQ5D Data. Health Economics, 19, 886-905. http://dx.doi.org/10.1002/hec.1608

[12] Knäuper, B. and Turner, P.A. (2003) Measuring Health: Improving the Validity of Health Assessments. Quality of Life Research, 12, 81-89. http://dx.doi.org/10.1023/A:1023589907955

[13] Weinberger, M., Kirkman, M.S., Samsa, G.P., Cowper, P.A., Shortliffe, E.A., Simel, D.L. and Feussner, J.R. (1994) The Relationship between Glycemic Control and Health-Related Quality of Life in Patients with Non-Insulin-Dependent Diabetes Mellitus. Medical Care, 32, 1173-1181. http://dx.doi.org/10.1097/00005650-199412000-00002

[14] Brown, D.W., Balluz, L.S., Giles, W.H., Beckles, G.L., Moriarty, D.G., Ford, E.S. and Mokdad, A.H. (2004) Diabetes Mellitus and Health-Related Quality of Life among Older Adults: Findings from the Behavioral Risk Factor Surveillance System (BRFSS). Diabetes Research and Clinical Practice, 65, 105-115. http://dx.doi.org/10.1016/j.diabres.2003.11.014

[15] El Achhab, Y., Nejjari, C., Chikri, M. and Lyoussi, B. (2008) Disease-Specific Health-Related Quality of Life Instruments among Adults Diabetic: A Systematic Review. Diabetes Research and Clinical Practice, 80, 171-184. http://dx.doi.org/10.1016/j.diabres.2007.12.020

[16] Vieta, A., Badia, X. and Sacristán, J.A. (2011) A Systematic Review of Patient-Reported and Economic Outcomes: Value to Stakeholders in the Decision-Making Process in Patients with Type 2 Diabetes Mellitus. Clinical Therapeutics, 33, 1225-1245. http://dx.doi.org/10.1016/j.clinthera.2011.07.013

[17] Kong, D., Ding, Y., Zuo, X., Su, W., Xiu, L., Lin, M., Rao, S. and Yu, S. (2011) Adaptation of the Audit of Diabetes-Dependent Quality of Life questionnaire to Patients with Diabetes in China. Diabetes Research and Clinical Practice, 94, 45-52. http://dx.doi.org/10.1016/j.diabres.2011.05.026 
[18] Prevolnik-Rupel, V. and Ogorevc, M. (2009) The Reliability and Stability of Slovenian Population Preferences for EQ-5D Health States in Time. Slovenian Medical Journal, 78, 633-640.

[19] Prevolnik-Rupel, V. and Rebolj, M. (2000) The Slovenian VAS Tariff Based on Valuations of EQ-5D Health States from the General Population. The 17th Plenary Meeting of the EuroQoL Group, Pamplona, 28-29 September 2000, 23-46.

[20] Rupel, V.P. and Ogorevc, M. (2012) The EQ-5D Health States Value Set for Slovenia. Slovenian Journal of Public Health, 51, 128-140. http://dx.doi.org/10.2478/v10152-012-0015-y

[21] Costa, F.A., Guerreiro, J.P. and Duggan, C. (2006) An Audit of Diabetes Dependent Quality of Life (ADDQoL) for Portugal: Exploring Validity and Reliability. Pharmacy Practice, 4, 123-128.

[22] Greiner, W., Weijnen, T., Nieuwenhuizen, M., Oppe, S., Badia, X., Busschbach, J., Buxton, M., Dolan, P., Kind, P. and Krabbe, P. (2003) A Single European Currency for EQ-5D Health States. The European Journal of Health Economics, 4, 222-231. http://dx.doi.org/10.2478/v10152-012-0015-y

[23] Kind, P., Brooks, R. and Rabin, R. (2005) Eq5d Concepts and Methods: A Developmental History. Springer, Berlin. http://dx.doi.org/10.1007/1-4020-3712-0

[24] Kind, P. (1996) The EuroQol Instrument: An Index of Health-Related Quality of Life. Quality of Life and Pharmacoeconomics in Clinical Trials, 2, 191-201.

[25] Prevolnik-Rupel, V. (2007) Vpliv Kvalitete Zivljenja na Postavljanje Prioritet in Učinkovitost Alokacije Sredstev v Zdravstvu. University of Ljubljana, Ljubljana.

[26] Buzeti, T. and Gobec, M. (2012) Health Inequalities in Slovenia. National Institute of Public Health, Ljubljana.

[27] Holmanová, E. and Žiaková, K. (2009) Audit Diabetes-Dependent Quality of Life Questionnaire: Usefulness in Diabetes Self-Management Education in the Slovak Population. Journal of Clinical Nursing, 18, 1276-1286. http://dx.doi.org/10.1111/j.1365-2702.2008.02602.x

[28] Soon, S.S., Goh, S.Y., Bee, Y.M., Poon, J.L., Li, S.C., Thumboo, J. and Wee, H.L. (2010) Audit of Diabetes-Dependent Quality of Life (ADDQoL) Chinese Version for Singapore Questionnaire: Reliability and Validity among Singaporeans with Type 2 Diabetes Mellitus. Applied Health Economics and Health Policy, 8, 239-249. http://dx.doi.org/10.2165/11313920-000000000-00000

[29] Mrevlje, F. (2006) Nekateri Kazalci Zdravstvenega Stanja Bolnikov s Sladkorno Boleznijo v Sloveniji v Letih 2005/ 2006. Slovenski Endokrinološki Kongres z Mednarodno Udeležbo, Bled, 21-22 September 2006, 28-32.

[30] Wee, H.-L., Tan, C.-E., Goh, S.-Y. and Li, S.-C. (2006) Usefulness of the Audit of Diabetes-Dependent Qualityof-Life (ADDQoL) Questionnaire in Patients with Diabetes in a Multi-Ethnic Asian Country. Pharmacoeconomics, 24, 673-682. http://dx.doi.org/10.2165/00019053-200624070-00006

[31] Zhang, X.H., Tan, K., Tan, H.H., Thumboo, J. and Li, S.C. (2012) Are English and Chinese Versions of the Audit of Diabetes-Dependent Quality of Life Equivalent? An Exploratory Study Based on the Universalist Approach. Value in Health Regional Issues, 1, 75-81. http://dx.doi.org/10.1016/j.vhri.2012.03.005

[32] Chung, J., Cho, D., Chung, D. and Chung, M. (2012) Assessment of Factors Associated with the Quality of Life in Korean Type 2 Diabetic Patients. Internal Medicine (Tokyo, Japan), 52, 179-185.

[33] Wang, H. and Yeh, M.C. (2012) The Quality of Life of Adults with Type 2 Diabetes in a Hospital Care Clinic in Taiwan. Quality of Life Research, 22, 577-584. http://dx.doi.org/10.1007/s11136-012-0178-7

[34] Collins, M.M., O’Sullivan, T., Harkins, V. and Perry, I.J. (2009) Quality of Life and Quality of Care in Patients with Diabetes Experiencing Different Models of Care. Diabetes Care, 32, 603-605. http://dx.doi.org/10.2337/dc08-1169

[35] Ostini, R., Dower, J. and Donald, M. (2011) The Audit of Diabetes-Dependent Quality of Life 19 (ADDQoL): Feasibility, Reliability and Validity in a Population-Based Sample of Australian Adults. Quality of Life Research, 21, 1-7.

[36] Lemon, S.C., Rosal, M.C. and Welch, G. (2011) Measuring Quality of Life in Low-Income, Spanish-Speaking Puerto Ricans with Type 2 Diabetes Residing in the Mainland US. Quality of Life Research, 20, 1507-1511. http://dx.doi.org/10.1007/s11136-011-9871-1

[37] Demirci, H., Cinar, Y., Bayram, N. and Bilgel, N. (2012) Quality of Life in Type II Diabetic Patients in Primary Health Care. Danish Medical Journal, 59, A4468-A4468.

[38] Borrott, N. and Bush, R. (2008) Measuring Quality of Life among Those with Type 2 Diabetes in Primary Care. The University of Queensland, Ipswich.

[39] Trief, P.M., Wade, M.J., Pine, D. and Weinstock, R.S. (2003) A Comparison of Health-Related Quality of Life of Elderly and Younger Insulin-Treated Adults with Diabetes. Age and Ageing, 32, 613-618. http://dx.doi.org/10.1093/ageing/afg105

[40] Lindau, S.T., Schumm, L.P., Laumann, E.O., Levinson, W., O’Muircheartaigh, C.A. and Waite, L.J. (2007) A Study of Sexuality and Health among Older Adults in the United States. New England Journal of Medicine, 357, 762-774. 
http://dx.doi.org/10.1056/NEJMoa067423

[41] Robinson, J.G. and Molzahn, A.E. (2007) Sexuality and Quality of Life. Journal of Gerontological Nursing, 33, 19.

[42] Wee, H.L., Tan, C.E., Goh, S.Y. and Li, S.C. (2006) Usefulness of the Audit of Diabetes-Dependent Quality-of-Life (ADDQoL) Questionnaire in Patients with Diabetes in a Multi-Ethnic Asian Country. Pharmacoeconomics, 24, 673682. http://dx.doi.org/10.2165/00019053-200624070-00006

[43] Blanchflower, D.G. and Oswald, A.J. (2008) Is Well-Being U-Shaped over the Life Cycle? Social Science \& Medicine, 66, 1733-1749. http://dx.doi.org/10.1016/j.socscimed.2008.01.030

[44] Realo, A. and Dobewall, H. (2011) Does Life Satisfaction Change with Age? A Comparison of Estonia, Finland, Latvia, and Sweden. Journal of Research in Personality, 45, 297-308. http://dx.doi.org/10.1016/j.jrp.2011.03.004 